\title{
Corpo, desejo e erotismo na narrativa da série de TV: Mandrake.
}

\author{
Tânia Montoro ${ }^{1}$ \\ (taniamontoro@unb.br) \\ Carolina Dumaresq ${ }^{2}$ \\ (carolina.dumaresq@gmail.com)
}

\begin{abstract}
Resumo
Este trabalho utiliza-se do referencial teórico dos estudos culturais, da teoria das representações sociais e da crítica feminista para analisar, sob a perspectiva dos estudos de gênero, a série televisão Mandrake, exibida no Brasil pelo canal HBO, nos anos de 2005 e 2007, com reprise em 2010. Investiga os significados atribuídos aos corpos masculinos e femininos que conformam identidades de gênero. A análise considerou elementos da gramática audiovisual como enquadramentos, ponto de vista; movimentos de câmera e construção de personagens. Verifica-se a existência de um olhar patriarcal, reforçando estereótipos de gênero e formas de estigmas acoplados ao desejo e consumo dos corpos femininos e masculinos.
\end{abstract}

Palavras - chaves: Televisão. Identidade de Gênero. Corpo. Audiovisual.

\section{Body, desire and eroticism in the TV series Mandrake's narrative.}

\begin{abstract}
This paper is based on the theoretical reference of cultural studies, the theory of social representations and the feminist criticism, to analyze, under the perspective of gender studies, Mandrake TV series, aired on HBO in Brazil, from 2005 to 2007, with a repeat in 2010. It investigates the meanings assigned to male and female bodies that conform gender identities. The analysis considered elements of the audiovisual grammar, such as frameworks, point of view, camera movement and character building. It was revealed the existence of a patriarchal look, reinforcing gender stereotypes and stigmas attached to the desire and consumption of female and male bodies.
\end{abstract}

Keywords: Television. Gender Identity. Body. Audiovisual.

Este artigo analisa, sob a perspectiva da critica feminista, a série de televisão Mandrake, produzida no Brasil, pelo canal fechado de televisão HBO nos anos de 2005 e 2007, com reprise em

\footnotetext{
${ }^{1}$ Doutora em Comunicação Audiovisual pela Universidade Autônoma de Barcelona com pós-doutorado em cinema na UFRJ. Professora e Pesquisadora do Programa de Pós - graduação da Faculdade de Comunicação e do Centro de Excelência em Turismo da Universidade de Brasília.

${ }^{2}$ Jornalista e mestre em Comunicação ( linha imagem e som) pela Universidade de Brasília.
} 
2010. A ficção foi filmada, em treze episódios, na cidade do Rio de Janeiro e exibida para América Latina e Estados Unidos pelo canal HBO Latin America e, em Portugal, pelo canal Fox. No decorrer da análise, investigam-se os sentidos que propiciam a construção e diferenciação dos corpos masculinos e femininos na conformação das identidades de gênero. Procura-se evidenciar de que maneira indivíduos "generificados" constroem relações de gênero, percebendo como se organizam, representam e são identificadas pelas dinâmicas culturais.

O trabalho utiliza-se do referencial teórico dos estudos culturais da Comunicação, da teoria das representações sociais e da crítica feminista para analisar as representações do corpo feminino como dispositivo de construção de diferentes espaços, usos e olhares em sua interação com a cidade do Rio de Janeiro, cartão postal identitário e imagético do país.

Nessa esteira, a série Mandrake apresenta-se como pertinente e atual objeto de estudo pela potencialidade de exploração de temas relativos ao universo urbano e que impactam nas configurações sociais nas quais os indivíduos estão imersos. È importante dar relevo à grande circulação de imagens do corpo nu feminino simbolizando o sensual e o erótico como aspectos constituintes da identidade cultural da cidade do Rio de Janeiro sedimentada cotidianamente pela mídia.

É no cotidiano onde as representações culturais são construídas mais freqüentemente, difundindo valores, expectativas e sentidos que ajudam a decifrar visões de mundo. A produção e circulação de mensagens na atualidade estão fortemente ligadas aos meios de comunicação massivos, especialmente à televisão. $\mathrm{Na}$ contemporaneidade, o intenso fluxo de imagens perpassando as relações cotidianas oferece antigas e novas formas simbólicas que orientam e organizam condutas. O sentido dado à existência humana é também definido pela mídia televisiva, uma vez que ela "não oferece modelo a imitar, mas se oferece como espelho em qual acreditamos estar refletida a nossa própria imagem" (KEHL, 2004, p. 20).

Ao oferecer modelos identitários, a televisão também cria sentidos de normalidade e desvios tomando como referência expectativas de comportamentos desempenhados por mulheres e homens. Decorre daí a relevância em examinar a forma como a televisão vem sendo incorporada no cotidiano das pessoas e como o cotidiano é incorporado pela televisão a partir da perspectiva de gênero.

A teórica Teresa de Lauretis entende o conceito de gênero como produto e processo de certo número de tecnologias sociais, discursos e práticas institucionalizadas e cotidianas. Por não 
existirem, a priori, nos seres humanos, nem a sexualidade, nem o gênero seriam propriedades orgânicas, mas "o conjunto de efeitos produzidos em corpos, comportamentos e relações sociais" (LAURETIS, 1994, p. 208).

Compreendido dessa forma, o conceito de gênero é um importante eixo de análise na interpretação dos processos identitários. Os estudos culturais da comunicação indicam que as identidades contemporâneas não são fixas e estão em permanente transformação. Dessa forma, o sujeito cartesiano proposto pelo iluminismo revela-se, na atualidade, múltiplo, uma vez que agrega, a um só tempo, diversas identidades. Reconhecer a fragmentação dos sujeitos é admitir que eles não se posicionam frente a apenas um eixo de diferenciação a partir do qual se poderia dizer que possuiriam uma identidade definitiva e única.

Nessa perspectiva, gênero constitui uma dimensão identitária que permite compreender as significações agregadas ao masculino e ao feminino dadas pelos sistemas de representação. A televisão, como local privilegiado de produção de sentidos, atua fixando significados àquilo que veicula

Primeiro, ela (a mídia) é o vetor de transmissão da linguagem, portadora em si mesma de representações. Em seguida, ela incide sobre os aspectos estruturais e formais do pensamento social, à medida que engaja processos de interação social, influência, consenso ou dissenso e polêmica. Finalmente, ela contribui para forjar representações que, apoiadas numa energética social, são pertinentes para a vida prática e afetiva dos grupos (JODELET, 2001, p. 32).

A narrativa televisiva é construída a partir da articulação de diferentes linguagens, o que faz dessa mídia um complexo sistema de representação. A linguagem verbal articula-se à sonora e aos diferentes sistemas de significações visuais. No sentido de trabalhar com os códigos da linguagem audiovisual, que possui gramática própria, destacamos para análise elementos da composição do quadro audiovisual ressaltando composição cênica dos objetos, construção da narrativa audiovisual; fragmentos discursivos; modalidades de silenciamentos e a dimensão sonora que imprimi dramaticidade e emoção ao fragmento audiovisual ficcional.

\section{A série Mandrake}

A série Mandrake foi ao ar às $23 \mathrm{~h}$ aos domingos, pelo canal pago $\mathrm{HBO}$, entre os anos de 2005 e 2007. A produção foi dividida em duas fases, que compuseram uma primeira temporada. Em 2005 foram exibidos os oito primeiros capítulos e, em 2007, os cinco últimos, com cinqüenta 
minutos cada. Realizada pela produtora brasileira Conspiração Filmes, a ficção televisiva é uma adaptação livre da obra do escritor brasileiro Rubem Fonseca.

A trama traz o personagem-título Mandrake, cujo nome de batismo é Paulo Mendes. Interpretado pelo ator Marcos Palmeira, ele é um advogado criminalista que transita entre o submundo do crime no Rio de Janeiro e a alta sociedade resolvendo casos de chantagem e extorsão. Suas relações afetivas são marcadas pelo desejo de sedução e de prazer erótico e sexual. Como define o narrador do episódio de apresentação da série, "Mandrake é um homem de muitas mulheres e poucos amigos, suas principais armas são a esperteza e a sedução"3.

Esse traço de personalidade é também destacado por um dos diretores da série, o músico e cineasta Tony Bellotto: "Ele tem as características de um típico carioca: é um bon vivent e amante das mulheres. Uma das características principais do Mandrake é que ele é um mulherengo"4.

A produção foi rodada com recursos do cinema noir. O crítico Jean-Pierre Chartier publicou, em 1946, na revista La revue du Cinema os elementos básicos do gênero: "A narração na primeira pessoa, a presença da mulher fatal, a importância da atração sexual nos enredos e o pessimismo desesperante dos personagens" (apud Mattos, 2001, p. 12-13).

O personagem mais popular do escritor Rubem Fonseca surgiu pela primeira vez no conto $O$ Caso de F.A, publicado, em 1969, no livro Lucia Mcartney. Em 1975, o personagem voltou à narrativa do escritor no conto Dia dos Namorados, do livro Feliz Ano Novo. Quatro anos depois, o livro O Cobrador (1979) foi lançado com o conto Mandrake. Até então personagem de narrativas curtas, em 1983, o detetive ganhou o protagonismo literário no romance A grande arte. Mandrake aparece ainda no livro E do meio do mundo prostituto, só amores guardei ao meu charuto (1997) e no livro Mandrake, a Bíblia e a Bengala (2005).

Estudiosos da literatura de Rubem Fonseca, como Barros (2007) e Vidal (2000), apontam semelhanças entre Mandrake e o detetive Philip Marlowe, criação do escritor Raymond Chandler. Ambos compreendem o protagonista brasileiro como um duplo do detetive americano. "Como o detetive Philip Marlowe, esse primeiro herói de Fonseca é um solitário confinado ao espaço exíguo entre duas desordens: a violência dos marginais e a violência legalizada" (VIDAL, 2000, p. 96).

O personagem também saiu das histórias em quadrinhos. Na arte sequencial, Mandrake é um famoso mágico criado pelo roteirista norte-americano Lee Falk, em 1934. Mestre do ilusionismo, o

3 Retirado do episódio especial sobre os bastidores da série, exibido em 18/11/2007, pela HBO.
4 Retirado do episódio especial sobre os bastidores da série, exibido em 18/11/2007, pela HBO. 
personagem dos quadrinhos detinha um poder de hipnose instantânea, além da elegância, sedução e virilidade como traços de sua personalidade. As altas doses de erotismo do personagem de Rubem Fonseca derivam também dos filmes noir clássicos, nos quais as personagens femininas "são pintadas com as cores fortes da femme fatale, a perigosa traidora, sempre pronta para desgraçar a vida do homem, incautamente por ela seduzido" (BARROS, 2007, p. 32). Etimologicamente, o nome Mandrake deriva de mandrágora ${ }^{5}$, uma planta cujas frutas e folhas têm supostos poderes afrodisíacos. Qualidade que justificaria a habilidade em seduzir as mulheres que cruzam o seu caminho.

\section{Corpo, sexualidade, desejo e erotismo na série Mandrake}

Não é novidade a exploração de temáticas associadas à sexualidade humana e a atos sexuais ${ }^{6}$ pelos meios de comunicação. No livro História da Sexualidade: a vontade de saber, Foucault (2007) constrói uma economia geral do discurso sobre o sexo como forma de perceber a lógica que rege a produção de saberes que giram em torno dele. De acordo com o autor, houve, na linha evolutiva da história, uma explosão discursiva sobre o sexo com o intuito de controle e vigilância do exercício da sexualidade. A partir do século XVIII, diferentes instituições, como a medicina, a psicanálise, a instituição religiosa, o Estado - com as taxas de natalidade e a economia política da população - e, mais recente, os meios de comunicação contribuíram para a multiplicação dos discursos sobre o sexo como forma de estabelecer padrões de funcionalidade e utilidade.

Através de tais discursos multiplicam-se as condenações judiciárias das perversões menores, anexou-se a irregularidade sexual à doença mental; da infância à velhice foi definida uma norma de desenvolvimento sexual e cuidadosamente caracterizado todos os desvios possíveis, organizaram-se controles pedagógicos e tratamentos médicos (FOUCAULT, 2007, p. 43).

Instaurava-se, a partir desse período, uma forma muito particular de poder disciplinar que gerava uma sensação de constante patrulhamento por meio do controle do corpo de modo a mantêlo dócil e produtivo. Decorre daí o "dispositivo da sexualidade", conceito forjado pelo autor para designar o conjunto de práticas e discursos produzidos pelas instituições que concorrem para a

\footnotetext{
5 Em inglês, mandrágora é traduzido por mandrake.

6 Tomando como base Foucault, neste trabalho, sexualidade vai além do ato sexual, por envolver aspectos subjetivos, como a construção dos desejos e das relações sociais.
} 
normatização da sexualidade na sociedade. Esse dispositivo institui o sexo como a verdade maior sobre o indivíduo, uma vez que cria mecanismos de controle da carne, dos corpos e dos prazeres.

Na sociedade ocidental contemporânea, a explosão discursiva em torno do sexo configura-se como um marcador identitário, sobretudo porque é no corpo biológico onde essas marcas produzem significados. A proliferação de imagens e discursos sobre o sexo gera corpos biológicos, sexualidades e práticas sexuais, instâncias que produzem diferenças, polaridades e padrões de vivências e subjetividades. Existem muitas formas de fazer-se mulher ou homem, embora seja preciso reconhecer que as possibilidades de viver prazeres e desejos corporais não estão livres de marcos regulatórios, são "sempre sugeridas, anunciadas, promovidas socialmente. Elas são também, renovadamente, reguladas, condenadas ou negadas" (FOUCAULT, 2007, p. 9). Nesse sentido, a sexualidade humana não pode ser vista apenas como uma questão pessoal, uma vez que é construída dentro de um terreno sócio-político e cultural passível de intervenções e controle.

São muitas as relações de poder que atravessam a sexualidade, nessa perspectiva, pode-se dizer que o poder atua sobre o corpo quando a ele agrega um sexo, tornando-o um corpo sexuado. Isso porque ao tomar um corpo como feminino ou masculino, o poder cria rótulos e categorias que enquadram as experiências sexuais e afetivas.

No seriado Mandrake, o corpo feminino é um locus de sensualidade, erotização e sedução, sendo ele o lugar onde se inscreve a sexualidade e onde se expressam as identidades de gênero. $\mathrm{O}$ exercício da sexualidade revela a forma como os significados são atribuídos ao encontro sexual, gerando sentidos que resultam nas diferenças de corpos e nas distintas posições identitárias.

Butler sublinha que a materialidade do corpo vai além da sua natureza física, pois aquilo que o diferencia morfologicamente está embebido de regras, normas e valores socialmente significados. “O sexo é, pois, não simplesmente aquilo que alguém tem ou uma descrição estática daquilo que alguém é: ele é uma das normas pela qual 'alguém' simplesmente se torna viável, é aquilo que qualifica um corpo para a vida no interior do domínio da inteligibilidade” (BUTLER, 2007, p. 155).

Nesse sentido, percebe-se no desenvolvimento da trama a importância do corpo sexualizado, compreendido como um corpo que significa por meio do desejo sexual, como princípio norteador das relações de gênero. A narrativa audiovisual atribui significados culturais e sociais aos corpos em circulação, perceptíveis a partir da roupa que cobre ou desnuda, dos acessórios que o adornam e imprimem formas de pertencimento e exclusões ainda, da imagem que dele se produz. 
A análise que se realiza toma a(s) corporalidade(s) como elemento destacado para análise das relações de gênero nos fragmentos fílmicos da serie de televisão Mandrake. Indicam a presente na narrativa audiovisual de três vertentes de construção das relações sexuais e sociais de gênero marcadas no território do corpo e desejo; corpo e idade feminina e corpo e prostituição. Sobre o suporte da corporalidade o consumo do corpo feminino feticizado orienta os contornos representacionais da narrativa.

\subsection{Corpo desejado}

Duas imagens complementares e não-excludentes projetam-se a partir do "corpo desejado". A primeira delas refere-se ao corpo feminino, focado na juventude e valorização da forma física, difundido pela mídia como um ideal a ser perseguido por mulheres. A aparência cria dessa forma padrões físicos de corporalidades estimulados, em grande medida, por personalidades midiáticas, como atrizes e modelos que, lançadas à condição de celebridades, apresentam-se como modelos de beleza invejável e desejável. É, portanto, um corpo sem marcas, sem rugas, estrias, celulites; e sem excessos de gordura. Roupas, cores e acessórios funcionam como uma espécie de embalagem cuja função é valorizar detalhes anatômicos; fragmentos corporais dotados de sensualidade.

A representação das mulheres desejáveis é marcada pela exibição do corpo como emissário de prazer e sedução. Falar em emissário é reconhecer que existe um destinatário, nesse caso, o sujeito masculino e orientando os sentidos em circulação. . Tem-se assim o segundo sentido atribuído ao "corpo desejado", compreendido como aquele destinado ao olhar masculino, servindolhe ao consumo visual. A nudez ou a semi-nudez configura-se em um recurso utilizado na representação das relações sexuais e sociais de gênero com ênfase na associação entre corpo nu e "sarado" como a única forma de sedução e sensualidade. Desta feita o corpo é destituído de sua alma, sua experiência, sua história.

\subsection{Corpo coroa}

A expressão "corpo coroa" foi cunhada pela pesquisadora, antropóloga, Mirian Goldenberg (2008), que há mais de dez anos estuda a cultura do corpo na cidade do Rio de Janeiro. Em 2007, seu foco recaiu sobre a análise do significado do envelhecimento no Brasil, comparando desejos e perspectivas das mulheres cariocas, com idade entre cinqüenta e sessenta anos, com as alemãs, as inglesas e as espanholas. Alguns anos antes, a pesquisadora fundara o grupo "Coroas", como forma 
de criar uma resistência política lúdica. A idéia era usar um termo usualmente aplicado de forma pejorativa como categoria de afirmação identitária. COROAS/JUVENTUDE/INFANCIA.

Entende-se por "corpo coroa" aquele cujas marcas do tempo evidenciam-se na dimensão material do corpo humano, produzindo significados ao processo de envelhecimento. Observa-se que, na produção audiovisual, a velhice é representada como um momento de perda do capital físico. Essa forma de representação resulta de uma leitura biologizante do corpo humano na qual atrela, unicamente, o corpo feminino ao seu aparelho reprodutor.

Compreendendo-o como um objeto histórico e cultural, o corpo funciona como o espelho de um determinado tempo. No século XXI, o corpo jovem e musculoso, construído pelo consumo e pela Indústria do entretenimento, apresenta-se como representante da sociedade contemporânea. Nesse contexto, há um esforço de deslocamento do corpo envelhecido pelos poderes disciplinadores, que, a um só tempo, o afastam do corpo ideal e o excluem do meio social, forjando uma identidade em que a expressão da velhice corresponde tanto ao declínio da atividade produtiva, como da atividade sexual, reprodutiva e, estética . E pergunta-se ao seriado porque não há beleza, sedução e poesia no corpo experimentado pelo cotidiano dos anos da vida.?

Desta forma, o olhar midiático da série também exclui: conduz para a invisibilidade e para o silenciamento de corpos femininos que não se configuram dentro de um único padrão estético de beleza - no caso do seriado, impedindo a visibilidade da nudez do corpo maduro como elemento de construção de simetrias de gênero.

\subsection{Corpo prostituído}

O corpo prostituído é aquele inserido dentro da lógica de mercado, em que o desejo e o sexo são os produtos comercializados. Nesse sentido, a exploração da sexualidade da mulher acentua o processo de mercantilização do corpo feminino, reificando-o para o uso e controle do poder masculino.

Do ponto de vista do poder disciplinador, a prostituição é uma atividade transgressora das normas estipuladas pelo meio social e daquilo que é esperado pela conduta feminina. Enquadrada como uma atividade desviante, tendo a conduta sexual como referência, a prostituição carrega a marca do estigma, extensiva ao indivíduo que a pratica. Nesse sentido, o estigma emerge como um 
dispositivo de controle utilizado para colocar refreios às identidades desviantes ou a práticas consideradas depreciativas, incutindo nos corpos estigmatizados a sensação de menos valia social.

Submetido às leis da oferta e da procura que regulam todo e qualquer mercado, o valor dos corpos prostituídos é atribuído segundo uma escala de sua performance física. Os mais valorizados em geral são corpos trabalhados por meio de exercícios físicos e intervenções estéticas, aproximando-o de padrões hegemônicos que se favorecem de tipologias e formas de representação. Uma característica que se sobressai refere-se à associação da celebração de formas de sedução, fetiches, vestimentas e adornos e as formas de visualidades de objetos de sedução e consumo sexual.

\section{Representação audiovisual e identidade de gênero}

Buscam-se, nesse tópico as representações que impactam na construção de uma imagem de mulher sexualmente desejável, "que, além de ser identificada como aquilo que todos os homens devem aspirar a possuir, pode ser incorporada pelas mulheres como aquilo que elas devem ser ou tornar-se para poder obter alguma valorização social” (ADELMAN, 2005, p. 229).

Para aprofundar essa questão, toma-se para análise a cena que abre o episódio "Yag", exibido em 20/11/2005, com reprise em 29/01/2010. Participam da ação os personagens Mandrake, Leon Wexler (Luís Carlos Miéle), Zé Carlos (Edgar Amorin), Marcelo Pereira (Maurício Gonçalves), Júnior (Marcelo Adnet) e Flávia Guimarães (Malu Galli). O grupo de advogados está reunido para um happy hour no Bar do Zé ${ }^{7}$, onde participam de um jogo rotineiro entre amigos: dar notas às mulheres que frequentam o lugar.

A cena tem início ainda na música de abertura do episódio, nos créditos iniciais. Com a tela em fade out, ouve-se a voz em off dos personagens Zé Carlos e Júnior:

- Zé Carlos: Aquela ali, ó.

- Júnior: Rapaz, interessante.

$\mathrm{Na}$ primeira referência imagética, surge em close a imagem de nádegas femininas que se movimentam. A câmera percorre o corpo da personagem de baixo para cima e encontra o rosto da mulher no exato instante em que ela vira-se para acender um cigarro. Um enquadramento médio revela ao fundo garrafas, copos, trânsito de garçons, revelando que a personagem está no balcão de

\footnotetext{
Bar do Zé é o espaço, no Centro da Cidade, onde o protagonista encontra seus colegas nos finais de tarde, após o expediente de trabalho.
} 
um bar. A câmera movimenta-se registrando a mulher em diversos ângulos e planos de detalhes: de perfil, ajeitando o decote, com o cigarro nos lábios, beijando o namorado que acabara de chegar. Acompanhando a câmera, o diálogo prossegue em off até certo momento, quando cada personagem é enquadrado em plano próximo, em um movimento de apresentação de cada um deles. Sabe-se, então, que os amigos estão sentados em uma mesa em frente ao balcão. O diálogo desenvolve-se:

- Júnior: ih, nota cinco.

- Mandrake: Cinco? Que que é isso, Júnior?

- Júnior: Não gostei, não achei ela maneira de rosto. Qual o problema? Ainda por cima, fuma e bebe.

- Flávia: Maneira de rosto, Júnior? Mulherão. Nota nove.

- Júnior: Nove também, não, Flavinha. Na hora de beijar fica aquele bafo, aquela "nhaca".

- Mandrake: Você não entende nada de mulher.

- Flávia: Eu entendo.

- Mandrake: A diferença entre a mulher feia e a mulher bonita é que a mulher bonita confia tanto na beleza, que acaba ficando fria, isolada no universo da perfeição.

- Flávia: As feias são melhores amantes porque elas estão sempre atentas, se entregam mais. $\mathrm{O}$ corpo é tudo que elas têm.

- Zé Carlos: As feias fodem melhor, é isso?

- Flávia: É.

- Mandrake: Não existe mulher feia, Zé. Toda mulher tem seu encanto.

- Marcelo: Nota 8.

- Júnior: Aí, vocês têm razão. Eu vou mudar meu voto, 7,5.

Essa cena revela um recurso explorado em toda a série e que, por isso mesmo, pode-se apontar como a forma recorrente selecionada para representar a concepção da questão de gênero presente na narrativa do seriado. São imagens em primeiro plano de partes do corpo feminino, associadas quase sempre a uma sexualidade saturada, pronta para emergir. Weeks afirma que a linguagem da sexualidade é masculina, legitimando um modelo masculino dominante de sexualidade. "Os homens são os agentes sexuais ativos, as mulheres, por causa de seus corpos altamente sexualizados, ou apesar disso, eram vistas como meramente reativas" (WEEKS, 2007, p. 41).

Na cena em discussão, observa-se a tentativa de definir a personagem feminina anônima (e motivo de observação do grupo de amigos) em termos de dualidades mecanicistas bonita/ feia, corpo sexualmente atraente/ corpo não sexy; sedutora/ não sedutora. No fragmento do diálogo, Flávia Guimarães, que interpreta uma personagem lésbica, estabelece uma relação entre mulheres feias e boas amantes, contribuindo para a leitura de que o comportamento feminino é determinado 
por padrões corporais. Esse mecanismo é o mesmo utilizado nas associações entre beleza e fragilidade como virtudes femininas ou ainda na representação de mulheres feias como más. No que diz respeito às representações femininas desse episódio, as associações são tecnicamente elaboradas; há uma manipulação da linguagem audiovisual de modo a produzir metáforas visuais.

A câmera mostra em enquadramentos generosos partes do corpo feminino que funcionam como um termômetro para medir o grau de sexualidade da personagem. As notas atribuídas lembram um jogo no qual é testado o desempenho da mulher em construir-se atrativa para o olhar do outro. Nesse caso, a identidade de gênero, construída pelo olhar do outro é baseada na morfologia do corpo feminino e na sua capacidade de seduzir e despertar desejos e vontades.

Da mesa do bar, os amigos estabelecem critérios para dar nota à personagem feminina. Júnior avalia que ela merece nota cinco porque "não é maneira de rosto", também porque "fuma e bebe". "Na hora de beijar fica aquele bafo, aquela "nhaca", reforça o advogado. Nesse sentido, fumar e beber, hábitos praticados pelo próprio grupo, é percebido como um comportamento inadequado para o feminino, mas perfeitamente aceitável e incentivado entre os personagens masculinos. Essa relação é acentuada quando a câmera enquadra o rosto da anônima soltando fumaça, ato repreendido por Júnior, para, em seguida, enquadrar o personagem Mandrake, que fuma um charuto elegantemente.

Para dar ênfase às diferentes partes do corpo, ressaltando detalhes e escondendo outros, participam desse processo adereços, vestimentas, maquiagem. Não por acaso, a personagem anônima usa um vestido vermelho decotado colado ao corpo, criando um plano de percepção para o quadro em movimento. Esses elementos são agenciadores de forças que impulsionam o olhar do receptor para o que a câmera quer mostrar. Daí porque a personagem "não é maneira de rosto", essa é uma forma de hierarquizar informações, acentuando detalhes (nádegas movimentando-se em um vestido vermelho) e relegando outros (rosto).

No caminho oposto, apresenta-se o personagem Mandrake, bem como os demais personagens masculinos representados no seriado, com raras exceções. Esses personagens sempre aparecem vestidos, na sua maioria, com paletós de cor sóbria. Outro dado que tem uma ligação íntima com a sexualidade do personagem é o charuto, que, a exemplo desse episódio, é presença constante na ficção televisiva. Barros ( 2007, p. 35) dá relevo aos contos e romances do escritor Rubem Fonseca permeado por objetos que adquirem status fetichista a a longo das narrativas: “Charutos, garrafas de vinho, bengalas, facas, presentes na história que têm Mandrake como 
personagem indica uma representação fálica da exacerbada eroticidade do advogado". Seria uma forma também de representação da masculinidade em oposição à feminilidade. A associação de objetos aos órgãos sexuais masculinos foi discutida por Freud (apud MISSE, 1981, p. 35), quando o pênis é comparado:

a objetos que têm, como ele, a faculdade de poder penetrar no interior de um corpo e causar feridas: armas pontiagudas de todo tipo, facas, punhais, lanças e sabres, ou também armas de fogo, tais como fuzis e pistolas, particularmente aquela que por sua forma presta-se especialmente para esta comparação, o revólver.

Se a composição do protagonista conta com apelo a objetos fálicos, as personagens femininas contam com objetos de formas arredondas ou vazadas para simbolizar os órgãos genitais femininos, seus equivalentes e suas funções.

\section{Considerações finais}

A análise do seriado Mandrake identifica alguns padrões de reprodução das identidades de gêneros nas narrativas audiovisuais. Sob o suporte do corpo e da sexualidade, atrelados ao desejo, à sedução e ao erotismo, edificam-se as tramas dos episódios, fundando alicerces para a construção de um olhar masculino na composição das personagens femininas. Verifica-se a importância dada ao encontro sexual entre homens e mulheres, prática que no seriado naturaliza e enquadra corpos sexuados em termos exclusivamente biológicos, pautados pela anatomia corporal. A centralidade ocupada pelas questões de sexualidade no produto televisivo demonstra o domínio do "dispositivo da sexualidade" (FOUCAULT, 2007, p. 88) nos dias atuais, que faz do ato sexual e dos discursos sobre o sexo um componente de controle dos corpos por serem eles o local onde se manifestam os prazeres e os desejos. Percebe-se que essas duas dimensões são classificadas em termos de permitido e não permitido a um e outro gênero, de modo a inibir escolhas individuais.

Vale ressaltar que o funcionamento da mídia tenta engendrar a sensação de realidade, utilizando-se de códigos já familiarizados e informações amplamente divulgadas. Portanto, recorrer a temas que envolvem o erótico, o desejo e a sedução, manipulados em diversos suportes pela Indústria Cultural e do entretenimento, é uma forma de promover identificação com o público e assegurar o consumo da mensagem midiática. Ao "vender" um produto, a televisão agrega a ele valores e idéias que significam por meio de imagens, estabelecendo com elas uma relação de total dependência. No seriado, o erotismo se expressa na imagem do corpo feminino, explicitando estratégias de representação que destituem mulheres de subjetividade e que promovem corpos a 
protagonismos cênicos. Dessa forma, o corpo feminino é suporte para os fundamentos do olhar do outro, externo, idealizado e normatizado em níveis sociais e sexuais.

A análise das cenas e fragmentos fílmicos, selecionados para o estudo, apontou que os discursos e imagens relacionando corpo, sexualidade e identidade de gênero operam atribuindo marcas corporais generificadas a personagens masculinos e femininos, configurando-se em demarcadores de fronteiras identitárias. Também chama atenção a presença de objetos que exercem uma dupla função: fetichiza relações de gênero e atribui qualidade ao feminino e ao masculino. Partes do corpo feminino, investidas de sexualidade, são fragmentadas em closes e planos de detalhes de modo a orientar a leitura preferencial da narrativa. Os corpos femininos estabelecem sentidos e identidades para a cidade do Rio de Janeiro e operam como suportes de construções de repertórios imagéticos.

As mulheres protagonizam cenas em que se apresentam como irresistíveis ou fatais, enquanto os personagens criados pelas representações masculinas estão sempre interpretando e julgando, por meio de notas ou comentários, o desempenho do corpo feminino. Sem espaços de manobra, e outras formas de mediação, para a manifestação de seus próprios desejos, as mulheres realizam-se por meio da satisfação do olhar do outro - do masculino.

A manipulação dos códigos visuais na produção das cenas é observado 1 no tratamento diferenciado dado ao figurino masculino e feminino. Essa é uma forma de fixar para a imagem uma leitura sobre modelos identitários tomando como base comportamentos/ desempenhos esperados, ensinados e reproduzidos para ser homem objeto de desejo e, mulher - objeto de sedução. .

\section{Referências}

ADELMAN, Mirian. Vozes, olhares e o gênero do cinema. In: FUNCK, Susana B.; WIDHOLZER, Nara R. (Orgs.). Gênero e Discurso. Florianópolis: Ed. Mulheres; Santa Cruz do Sul: Edunisc, 2005.

BARROS, Antônio Carlos da S. A literatura na tela grande: obras de Rubem Fonseca adaptadas para o cinema. 2007. 113 f. Dissertação (Mestrado em literatura). Programa de Pós-graduação em literatura, Universidade de Brasília, Brasília, 2007.

BUTLER, Judith. Variações sobre sexo e gênero: Beauvoir, Wittig e Foucault. In: BENHABIB, Seyla, CORNELL, Drucilla. Feminismo como crítica da modernidade: releitura dos pensadores contemporâneos do ponto de vista da mulher. Rio de Janeiro: Rosa dos tempos, 1987.

BUTLER, Judith. Corpos que pesam: sobre os limites discursivos do "sexo". In: LOURO, Guacira

L. O corpo educado: pedagogias da sexualidade. 2. ed. Belo Horizonte: Autêntica, 2007.

FOUCAULT, Michael. A história da Sexualidade I: a vontade de saber. 18. ed. São Paulo:

Edições Graal, 2007.

Informação \& Comunicação, v. 14, n. 2, p. 214-227, jul./dez. 2011 
FREUD, Sigmund. O Futuro de uma ilusão: o mal-estar na civilização e outros trabalhos. Rio de Janeiro: Imago, 2006. (Coleção Sigmund Freud, 21).

GOLDENBERG, Mirian. Coroas: corpo, envelhecimento, casamento, infidelidade. Rio de Janeiro: Record, 2008.

HALL, Stuart. Identidade cultural na pós-modernidade. 10. ed. Rio de Janeiro: DP\&A, 2005. ; SOVIK, Liv (Org.). Da diáspora: identidades e mediações culturais. Belo Horizonte:

Editora UFMG, 2006.

JODELET, Denise (Org.). As representações sociais. Rio de Janeiro: Editora Uerj, 2001.

KEHL, Maria Rita; BUCCI, Eugênio. Videologias. São Paulo: Boitempo, 2004.

LAURETIS, Teresa de. A tecnologia do gênero. In: HOLLANDA, Heloisa B. de (Org.).

Tendências e impasses: o feminismo como crítica da modernidade. Rio de Janeiro: Rocco, 1994.

MATTOS, A. C. Gomes de. O outro lado da noite: filme noir. Rio de Janeiro: Rocco, 2001.

MISSE, Michel. O estigma do passivo sexual. 2. ed. Rio de Janeiro: Achiamé, 1981.

MONTORO, Tânia S. Protagonismo de gênero nos estudos de cinema no Brasil. In: Revista

Lumina, Juiz de Fora, v. 7, n. 12, UFJF, 2010. Disponível em: <www.ppgcomufjf.bemvindo.net.lumina>.

VIDAL, Ariovaldo José. Roteiro para um narrador. São Paulo: Ateliê editorial, 2000. WEEKS, Jeffrey. O corpo e a sexulidade. In: LOURO, Guacira L. O corpo educado: pedagogias da sexualidade. 2. ed. Belo Horizonte: Autêntica, 2007. 